\title{
Thai Youth Travel Forms: Green Values and Environment-Friendly-Travel Values Measurement ${ }^{*}$
}

\author{
Noppamash Suvachart \\ Khon Kaen University, Khon Kaen, Thailand
}

\begin{abstract}
This research has the objective for studies the youth travel form predispositions, with green consumers values and environment-friendly-travel (EFT) values measurement. To classify the youth travel by green values level and separate green youth from the not so green. This research also investigates the role of leisure activities toward EFT activeness categories. The main research instrument employed for this study was questionnaires that were self-administered to 900 respondents. A respondent must be 19-24 years old. The results showed high green consumer values $(\bar{X}=2.72)$, and high EFT values $(\bar{X}=2.68)$. There were statistically significant relationship between green consumer values and EFT values. When classified the youth by green shading, there were five major forms of EFT travel: very dark green, dark green, medium green, light green, and very light green. We found that $65.6 \%$ of youth were dark green group, $25.7 \%$ were medium green group, $7.8 \%$ were very dark green, $0.8 \%$ were light green group, and $0.2 \%$ were very light green group. There were no statistically significant differences based on age, gender, education, and income. The tourism area preference was the importance factor of distinguish between these groups.
\end{abstract}

Keywords: Thai youth travel pattern, environment-friendly travel, tourism measure

\section{Introduction}

The ecological sustainability of tourism has emerged as one of the most widely discussed and debated concepts within the broad tourism sector. The central objective of sustainable tourism research has been to identify how an economically viable tourism industry can be developed and maintained at a destination while minimizing adverse environmental impacts and in doing so, preserve the destination's natural and cultural resources for both residents and future generations of tourists. Global concern about environmental sustainability and climate change has increased in recent years and is now one of the most widespread social issues in Thailand. Evidence exists that concern about the quality of life for future generations via increasing awareness of the impacts of the use of household products, car emissions, long haul travel, and over-development is encouraging consumers to be more cautious about the type of products and services they purchase. Because of the environmental impacts, The Tourism Authority of Thailand (TAT) has provided educational and campaign programs. The programs name is seven greens project. The objectives of project

\footnotetext{
* Acknowledgment: This research is a part of project: The future of sustainable tourism due to the youth travel form predispositions. The author thanks the Management Science Faculty, Khon Kaen University for funding this project. The valuable comments of three anonymous referees are appreciated.

Noppamash Suvachart, D.B.A., Associate Professor of Management Science Faculty, Khon Kaen University.

Correspondence concerning this article should be addressed to Noppamash Suvachart, Management Science Faculty, Khon Kaen University, Khon Kaen 40001, Thailand. E-mail: snoppa@kku.ac.th.
} 
were to promote sustainable development and eco-friendly travel by providing programs that help tourist, travel-related companies, and communities protect the environmental, sociocultural, and economic needs of the places they visit. The seven greens concept which are including green heart, green logistics, green attraction, green community, green activity, green service, and green plus. Although there are many campaigns whether the environmental concerns of The Tourism Authority of Thailand (TAT), there is evidence that some television program discloses the impact of resort in the lake or campaign against tourism development that destroys the natural environment. While supply-side measures have attracted most attention, a complementary approach to reducing tourism's ecological footprint at a destination may be available in the form of demand-side approaches, which are based on the assumption that tourists have different ecological footprints and that the "size" of this footprint is a personal characteristic of each tourist and a function of how tourist behave environmentally during their visit (Carrus et al., 2005, Kals et al., 1999). According to Wearing and Neil (1999), there are two primary groups of characteristics, which will assist in exploring what features distinguish ecotourists: demographic and psychographic characteristics (which include a range of attitudinal and behavioral patterns). Likewise, behavioral segmentation was used in a study of overnight ecolodge patrons in Lamington National Park, Australia that resulted in three clusters of ecotourists (Weaver \& Lawton, 2002). They identified 10 characteristics that are commonly attributed to the hard and soft ideal types at either pole of an ecotourism spectrum. The "harder ecotourists" display characteristics such as strong environmental commitment, enhancive sustainability, specialized trips, long trips, small groups, physically active, physical challenge, few if any services expected, emphasis on personal experience and making own travel arrangements, while, the "softer ecotourists" exhibit characteristics such as moderate environmental commitment, steady state sustainability, multi-purpose trips, short trips, larger groups, physically passive, physical comfort, services expected, emphasis on interpretation and reliance on travel agents and tour operators. To these two groups may be added a third group which they refer to as "structured' ecotouists" who combined hard and soft characteristics. These "structured" ecotourists resemble the "harder" ecotourists in terms of their strong environment commitment, enhancive sustainability and being physically active whereas they resemble the "softer" ecotourists in the following factors: Multi-purpose trips, short trips, larger groups, services expected and emphasis on interpretation.

Young tourists will soon become adults, who, as they start their careers and their families, prefer to follow the travel patterns they established in their youth. Thus, this stage of life that is youth must contribute to building the social identity because today's young people will be tomorrow's full members of society. Therefore, socialization becomes a major objective because it is a process that will determine the individuals to share the society's values, which build multiple relationships with the constitutive members. As there is still much to learn about youth travel form predispositions in particular, the specific aims of this research are to describe the youth travel form predispositions, with green consumers values (Haws, Winterich, \& Rebecca, 2010) and environment-friendly-travel (EFT) values measurement which operationalisation' specifies the activities construct from the work of Weaver and Lawton (2002) and The Tourism Authority of Thailand (TAT) 2012. One of the earliest definitions of green consumers was published by Elkington and Hailes in 1988. Green consumers were described by their avoidance of products that have negative impacts. The impacts related to a number of concerns - the health of others or the environment; use of large amounts of resources; unnecessary waste; animal cruelty; use of materials from endangered species and/or adverse affects on other countries. Over time there has been substantial research to identify and segment these consumers (Peattie, 2001a). There were 
many researches attempted to explain these consumers in demographic terms which produced contradictor results. Another approach was to focus on the consumers' concerns and knowledge of the environment. However, this also proved to be inconsistent in isolating those who made green purchases. It was finally concluded that beliefs do not necessarily translate into purchasing, making it difficult to segment green consumers by demographics and/or values (Peattie, 2001b). The complexity surrounding the gap between values and action makes research of green consumerism difficult. A number of theories of consumer behavior and pro-environmental consumer behavior, in particular, have progressed. Choice, in an environmental context, is not straightforward as intentions and desires are moderated by social, cognitive, situation and cultural limitations (Jackson, 2004). The social psychological models show how cognitive processes and unconscious biases impact on behavior. For example, individual habits play a key role in moderating behavior. Unconscious and routine activities, such as taking waste to the rubbish bins and driving to work, can require interventions in the form of information and incentives (Jackson, 2004). The inconsistency and unpredictability of green consumers has been of interest to a number of researchers (McDonald et al., 2006) who present green consumers in terms of shades of green-from "very dark green" to "no green at all". McDonald et al. (2006) in their typology of green consumers, have distinguished three groups-Translators, exceptors, and selectors. In the field of psychology, green (or pro-environmental) behavior is described in terms of value-beliefs-norms (Steg, Dreijerink, \& Abrahamse, 2005). In the research of Steg et al. values were thought to activate beliefs in relation to human-environment relations which are then thought to affect specific beliefs consequences of behavior. In the Steg et al. (2005) framework, it is assumed that environmental behavior results from the general beliefs about the relationship between humans and the environment. These initial general beliefs then lead to awareness of consequences and the view that environmental conditions may threaten things the individual treasures and the idea that specific behavior can make a difference and reduce impacts. This research classifies the youth by shades of green and separate green from the not so green. The measurement of green consumers values and environment-friendly-travel (EFT) values has been criticized as measuring a plan to act rather than measuring an attitude also investigates the role of leisure activities toward EFT activeness categories. The conceptual framework is in Figure 1.

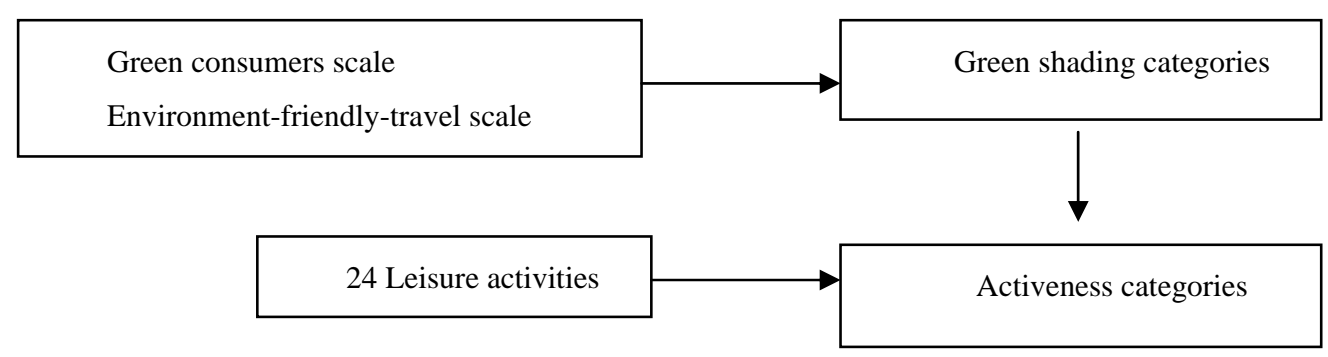

Figure 1. Conceptual framework.

\section{Methods}

\section{Questionnaire Development and Data Collection}

The study instrument (a questionnaire) consisted of two sections. The first part involved basic demographic and background data of the respondents. The second part comprised a fifty-three-item intended scale which included green consumer values which be designed by Haws et al., (2010). The environment-friendly-travel value which operationalisation' specifies the activities construct from the work of 
Weaver and Lawton (2002) and the Tourism Authority of Thailand (2012). The leisure activities preference was based on the work of Gotschi et al. (2010) which consist of 24 activities. Respondents were asked to state the extent of their agreement with each value that is commonly attributed to the green shading on Likert-type of summated rating scales. This section presented statement such as "It is important to me that the products I use do not harm the environment”. Scored on a 0-5 point strongly disagree to strongly agree scale. The main research instrument employed for this study was questionnaires that were self-administered to 900 respondents. A respondent must be 19-24 years old. The questionnaires were collected from respondents over the course of two months. The sociodemographic characteristics of the sample, 56\% were female and $44 \%$ were male, $23.7 \%$ were 20 years old, $20.4 \%$ were 19 years old, and the remaining 55.9\% were 22 years (18.8\%), 21 years (18.2\%), 24 years (9.6\%), and 23 years (9.3\%). Of the sample, $41 \%$ live at the middle region, $40 \%$ live at the northeastern and the remaining $19 \%$ live at the north (8\%), the east (7\%) and the south (4\%). Based on the tourism area, $26.8 \%$ preferred roaded-natural area, 20.6\% preferred nature primitive area, $19.3 \%$ preferred rural area, $14.9 \%$ preferred semi-primitive non-motorized area, $11.8 \%$ preferred roaded-modified area, and $6.7 \%$ preferred urban area.

\section{Statistical Evaluation}

Descriptive statistics, discriminant analysis, and chi square tests was run, using the Statistical Package for Social Sciences v.11.5. For all analyses, the minimum level of significance was set to $p<0.05$. Discriminant analysis was employed to determine the impact of the leisure activities on activeness categories and to assess which factors have a greater impact in explaining behavior. For calculation method of the discriminant analysis the case of mean score less than 3 were recoded into the category less active youth and the case of mean score more than 3 were recoded into the category active youth.

\section{Results}

\section{Green Values and Environment-Friendly-Travel Values Measurement}

As far as green consumers and EFT variables are concerned, the self-reported consumable and travel plan to act revealed that the Thai youth were high green consumer values $(\bar{X}=2.72)$, and high EFT values $(\bar{X}=$ 2.68). There were statistically significant relationship between green consumer values and EFT values. When classified the youth by mean of green shading, the travel forms of the sample can be found in Table 1 .

Table 1

Green Categories

\begin{tabular}{lllcc}
\hline Green categories & Mean & SD & Total & Percentage of total sample (\%) \\
\hline Very light green & 0.35 & 0.4945 & 2 & 0.2 \\
Light green & 1.50 & 0.1195 & 7 & 0.8 \\
Medium green & 2.28 & 0.1546 & 231 & 25.7 \\
Dark green & 2.79 & 0.2103 & 590 & 65.6 \\
Very dark green & 3.50 & 0.2003 & 70 & 7.8 \\
Total & 2.70 & 0.4009 & 900 & 100.0 \\
\hline
\end{tabular}

Note. SD: Standard Deviation.

As Table 1 shows, there were five major forms of EFT travel: very dark green, dark green, medium green, light green, and very light green. We found that $65.6 \%$ of youth were dark green group, $25.7 \%$ were medium 
green group, $7.8 \%$ were very dark green, $0.8 \%$ were light green group, and $0.2 \%$ were very light green group. The relation of sociodemographic characteristics (age, gender, education, and income and tourism area preference) to green shading categories was analyzed using Kruskal-Wallis test. There were no statistically significant differences based on age $\left(\chi^{2}=5.721\right.$, Sig. $\left.=0.221\right)$, gender $\left(\chi^{2}=2.216\right.$, Sig. $\left.=0.696\right)$, education $\left(\chi^{2}=0.497\right.$, Sig. $\left.=0.827\right)$, and income $\left(\chi^{2}=7.541\right.$, Sig. $\left.=0.110\right)$. The tourism area preference $\left(\chi^{2}=13.888\right.$, Sig. $\left.=0.008^{* *}\right)$ was the importance factor of distinguish between these groups with levels of significance 0.01 (values in parentheses with levels of significance ${ }^{* * *} p<0.001,{ }^{* *} p<0.01,{ }^{*} p<0.05$ ).

\section{Determining the Impact of Leisure Activities on Activeness Categories Using Discriminant Analysis}

For calculation method of the discriminant analysis the case of mean score less than 3 were recoded into the category less active youth and the case of mean score more than 3 were recoded into the category active youth. The travel forms of the sample can be found in Table 2 .

Table 2

Activeness Categories

\begin{tabular}{llllc}
\hline Activeness categories & Mean & SD & Total & Percentage of total sample (\%) \\
\hline Less active & 2.55 & 0.2946 & 712 & 79.1 \\
Active & 3.25 & 0.2337 & 188 & 20.9 \\
Total & 2.70 & 0.4009 & 900 & 100.0 \\
\hline
\end{tabular}

As Table 2 show, when classified the youth by mean score of EFT travel scale, there were $79.1 \%$ of youth were less active group, 20.9\% were active group. There were no statistically significant differences based on age, gender, education, and income $\left(\chi^{2}=4.926,0.415,1.950,8.159\right.$ and Sig. $=0.425,0.519,0.583,0.148$ respectively). Exploring the importance of leisure activities for activeness categories by compare means. As Table 3 show, the mean preference of 24 leisure activities variables were differently between groups, which mean preference of each leisure activities for less active youth was less than active youth. We explained that the leisure activities were less importance for less active group than active group significantly. The next step, using the discriminant analysis to find out the most importance leisure activity that classified these groups.

Table 3

Leisure Activities With Regard to Activeness Categories (1)

\begin{tabular}{|c|c|c|c|c|c|}
\hline Leisure Activities & Activeness categories & Mean & SD & $F$ & Sig. ${ }^{\text {a }}$ \\
\hline \multirow[t]{2}{*}{ Voluntary service } & Less active & 2.25 & 0.858 & 124.915 & $0.000^{* * *}$ \\
\hline & Active & 3.03 & 0.784 & & \\
\hline \multirow[t]{2}{*}{ Hiking/biking/outdoor } & Less active & 2.40 & 0.831 & 55.185 & $0.000^{* * *}$ \\
\hline & Active & 2.91 & 0.873 & & \\
\hline \multirow[t]{2}{*}{ Nutrition } & Less active & 2.42 & 0.811 & 62.417 & $0.000^{* * *}$ \\
\hline & Active & 2.95 & 0.829 & & \\
\hline \multirow[t]{2}{*}{ Health } & Less active & 2.46 & 0.822 & 90.801 & $0.000^{* * *}$ \\
\hline & Active & 3.09 & 0.734 & & \\
\hline \multirow[t]{2}{*}{ Special event } & Less active & 2.58 & 0.805 & 81.452 & $0.000^{* * *}$ \\
\hline & Active & 3.17 & 0.748 & & \\
\hline \multirow[t]{2}{*}{ Activities via mobilephone } & Less active & 2.31 & 0.894 & 42.503 & $0.000^{* * *}$ \\
\hline & Active & 2.80 & 0.977 & & \\
\hline \multirow[t]{2}{*}{ Nature protection and environment } & Less active & 2.56 & 0.782 & 98.098 & $0.000^{* * *}$ \\
\hline & Active & 3.20 & 0.780 & & \\
\hline
\end{tabular}


(Table 3 continued)

\begin{tabular}{|c|c|c|c|c|c|}
\hline Leisure Activities & Activeness categories & Mean & SD & $F$ & Sig. ${ }^{a}$ \\
\hline \multirow[t]{2}{*}{ Sport } & Less active & 2.57 & 0.891 & 64.204 & $0.000^{* * *}$ \\
\hline & Active & 3.14 & 0.789 & & \\
\hline \multirow[t]{2}{*}{ Car/motorbike } & Less active & 2.39 & 0.928 & 22.200 & $0.000^{* * *}$ \\
\hline & Active & 2.76 & 0.972 & & \\
\hline \multirow[t]{2}{*}{ Party } & Less active & 2.51 & 0.919 & 18.735 & $0.000^{* * *}$ \\
\hline & Active & 2.84 & 0.979 & & \\
\hline \multirow[t]{2}{*}{ Income } & Less active & 2.57 & 0.859 & 40.774 & $0.000^{* * *}$ \\
\hline & Active & 3.02 & 0.871 & & \\
\hline \multirow[t]{2}{*}{ Music and Singing } & Less active & 2.55 & 0.892 & 43.707 & $0.000^{* * *}$ \\
\hline & Active & 3.03 & 0.846 & & \\
\hline \multirow[t]{2}{*}{ Television } & Less active & 2.62 & 0.876 & 14.747 & $0.000^{* * *}$ \\
\hline & Active & 2.89 & 0.807 & & \\
\hline \multirow[t]{2}{*}{ Theater } & Less active & 2.25 & 1.022 & 10.264 & $0.001^{* *}$ \\
\hline & Active & 2.53 & 1.116 & & \\
\hline \multirow[t]{2}{*}{ Computer and videos } & Less active & 2.83 & 0.896 & 13.106 & $0.000^{* * *}$ \\
\hline & Active & 3.10 & 0.822 & & \\
\hline \multirow[t]{2}{*}{ Cinema } & Less active & 2.76 & 0.887 & 10.804 & $0.001^{* *}$ \\
\hline & Active & 2.99 & 0.887 & & \\
\hline \multirow[t]{2}{*}{ Travelling } & Less active & 2.55 & 0.950 & 31.707 & $0.000^{* * *}$ \\
\hline & Active & 2.99 & 0.965 & & \\
\hline \multirow[t]{2}{*}{ Dances } & Less active & 1.89 & 1.134 & 19.686 & $0.000^{* * *}$ \\
\hline & Active & 2.30 & 1.192 & & \\
\hline \multirow[t]{2}{*}{ Classic music } & Less active & 2.20 & 1.023 & 36.413 & $0.000^{* * *}$ \\
\hline & Active & 2.71 & 1.042 & & \\
\hline \multirow[t]{2}{*}{ Pop/rock music } & Less active & 2.62 & 0.897 & 5.454 & $0.02^{*}$ \\
\hline & Active & 2.80 & 1.025 & & \\
\hline \multirow[t]{2}{*}{ Art and Crafts } & Less active & 2.23 & 0.949 & 34.783 & $0.000^{* * *}$ \\
\hline & Active & 2.70 & 1.007 & & \\
\hline \multirow[t]{2}{*}{ Friends } & Less active & 2.61 & 0.892 & 11.392 & $0.001^{* *}$ \\
\hline & Active & 2.85 & 0.871 & & \\
\hline \multirow[t]{2}{*}{ Journals/comics } & Less active & 2.66 & 0.915 & 8.874 & $0.003^{* *}$ \\
\hline & Active & 2.89 & 0.977 & & \\
\hline \multirow[t]{2}{*}{ Reading books } & Less active & 2.50 & 0.962 & 33.563 & $0.000^{* * *}$ \\
\hline & Active & 2.96 & 0.978 & & \\
\hline
\end{tabular}

Notes. ${ }^{\mathrm{a}^{* * *}} p<0.001 ;{ }^{* *} p<0.01 ;{ }^{*} p<0.05$

As Table 4 show, the impact of 24 leisure activities was tested with discriminant analysis to explore the importance leisure activities preference factor of separate green youth (active group) from the not so green (less active group). There were statistically significant differences based on voluntary service, nature protection and environment, classic music, special event, sport, and reading books, respectively.

The final step of assessing group membership prediction accuracy, the cross-classification results (see Table 5) are shown that the discriminant functions (not shown here) in combination achieve a high degree of classification accuracy. The hit ratio for the analysis cases is $82.8 \%$ or the analysis accurately classified $82.8 \%$ of all the surveyed respondents. The less active cluster were misclassified $0.4 \%$. There were three cases tend to be active youth. The discriminant analysis results identified the total of 712 respondents $(79.11 \%)$ fell into the less active cluster, 188 (20.89\%) in the active cluster. 
Table 4

Variables Entered/Removed ( $a, b, c, d)$

\begin{tabular}{|c|c|c|c|c|c|c|c|c|c|}
\hline \multirow{3}{*}{ Step } & \multirow{3}{*}{ Importance variables entered } & \multicolumn{8}{|c|}{ Wilks’ Lambda } \\
\hline & & \multirow{2}{*}{ Statistic } & \multirow{2}{*}{ df1 } & \multirow{2}{*}{$\mathrm{df} 2$} & \multirow{2}{*}{ df3 } & \multicolumn{4}{|c|}{ Exact $F$} \\
\hline & & & & & & Statistic & df1 & df2 & Sig. \\
\hline 1 & Voluntary service & 0.878 & 1 & 1 & 898 & 124.915 & 1 & 898 & $0.000^{* * *}$ \\
\hline 2 & $\begin{array}{l}\text { Nature protection } \\
\text { and environment }\end{array}$ & 0.844 & 2 & 1 & 898 & 82.908 & 2 & 897 & $0.000^{* * *}$ \\
\hline 3 & Classic music & 0.828 & 3 & 1 & 898 & 62.037 & 3 & 896 & $0.000^{* * *}$ \\
\hline 4 & Special event & 0.814 & 4 & 1 & 898 & 51.096 & 4 & 895 & $0.000^{* * *}$ \\
\hline 5 & Sport & 0.808 & 5 & 1 & 898 & 42.478 & 5 & 894 & $0.000^{* * *}$ \\
\hline 6 & Reading books & 0.804 & 6 & 1 & 898 & 36.299 & 6 & 893 & $0.000^{* * *}$ \\
\hline
\end{tabular}

Notes. At each step, the variable that minimizes the overall Wilks' Lambda is entered. ${ }^{* * *} p<0.001$. a: Maximum number of steps is 48; b: Minimum partial $F$ to enter is 3.84; c: Maximum partial $F$ to remove is 2.71; d: $F$ level, tolerance, or VIN insufficient for further computation.

Table 5

Classification Matrices for Two-Group Discriminant Analysis (b, c)

\begin{tabular}{|c|c|c|c|c|c|}
\hline & & \multirow[t]{2}{*}{ Activeness categories } & \multicolumn{2}{|c|}{$\begin{array}{l}\text { Predicted group } \\
\text { membership }\end{array}$} & \multirow[t]{2}{*}{ Total } \\
\hline & & & 1 & 2 & \\
\hline \multirow[t]{4}{*}{ Original } & No. of cases & 1 Less active & 682 & 30 & 712 \\
\hline & & 2 Active & 125 & 63 & 188 \\
\hline & $\%$ & 1 Less active & 95.8 & 4.2 & 100.0 \\
\hline & & 2 Active & 66.5 & 33.5 & 100.0 \\
\hline \multirow[t]{4}{*}{ Cross-validated (a) } & No. of cases & 1 Less active & 679 & 33 & 712 \\
\hline & & 2 Active & 128 & 60 & 188 \\
\hline & $\%$ & 1 Less active & 95.4 & 4.6 & 100.0 \\
\hline & & 2 Active & 68.1 & 31.9 & 100.0 \\
\hline
\end{tabular}

Notes. a: Cross validation is done only for those cases in the analysis. In cross validation, each case is classified by the functions derived from all cases other than that case; b: $82.8 \%$ of original grouped cases correctly classified; c: $82.1 \%$ of cross-validated grouped cases correctly classified.

\section{Conclusions}

This research has the objective for studies the youth travel form predispositions, with green consumers values and environment-friendly-travel (EFT) values measurement. The main research instrument employed for this study was questionnaires that were self-administered to 900 respondents. A respondent were 19-24 years old. The results showed high green consumer values $(\bar{X}=2.72)$, and high EFT values $(\bar{X}=2.68)$. There were statistically significant relationship between green consumer values and EFT values. When classified the youth by green shading, there were five major forms of EFT travel: very dark green, dark green, medium green, light green, and very light green. We found that $65.6 \%$ of youth were dark green group, $25.7 \%$ were medium green group, $7.8 \%$ were very dark green, $0.8 \%$ were light green group, and $0.2 \%$ were very light green group. There were no statistically significant differences based on age, gender, education, and income. The tourism area preference was the importance factor of distinguish between these groups. To classify the youth travel by green values level and separate green youth from the not so green. The study indicated two different traveling patterns, these patterns were named, "less active youth”, and “active youth”. The discriminant analysis results identified 
the total of 712 respondents (79.11\%) fell into the less active cluster, 188 (20.89\%) in the active cluster. The traveling pattern "active youth" loads items to physical activities, access attributes, interacting with nature, natural location prefer. The pattern "Less active youth" includes items effective in less saving natural resources and less protect the environment. It revealed $20.89 \%$ of Thai youth were physically active, more environmentally aware and knowledgeable, service expected, multi-purpose and short trip, and moderate obedience of law and order. There were no statistically significant differences based on age, gender, education, and income. The findings show that the majority of Thai youth (79.11\%) tend to be nature-based tourist with less environmentally aware and knowledgeable. In fact, it could be argued that tourists in natural environments, even if they try to minimize their impact, may cause more environmental damage than tourist on a city tour. So, The Tourism Authority of Thailand (TAT), Ministry of Natural Resources and Environment, together with Ministry of Transport should cooperate to clearly decide the tourism areas as following the Recreation Opportunity Spectrum (ROS) before completely planned out the route, which link the tourism destinations. The road construction planning should be planned conform to the attributes of each destination in order to provide destination management with an additional tool to reduce the environmental impact of the tourism industry for both preserving environment and developing tourism sustainability.

\section{References}

Dolnicar, S., Crouch, G. I., \& Patrick, L. (2008). Environment-friendly tourist: What do we really know about them? Journal of Sustainable Tourism, 16(2), 197-210.

Elkington, J., \& Hailes, J. (1988). The green consumer guide. London: Victor Gollancz.

Gotschi, E., Yogel, S., Lindenthal, T., \& Larcher, M. (2010). The role of knowledge, social norms, and attitudes toward organic products and shopping behavior: Survey results from high school students in Vienna. The Journal of Environmental Education, 41(2), 88-100.

Jackson, T. (2004). Motivating sustainable comsumption: A review of evidence on consumer behavior and behavioral change. London: Policy Studies Institute. Report to the Sustainable Development Research Network.

Haws, K. L., Winterich, P., \& Rebecca, W. N. (2010). Seeing the world through GREEN-Tinted glasses: Motivated reasoning and consumer response to environmentally friendly products. Working Paper, Texas A\&M University, College Station, TX 77843.

McDonald, S., Oates, C., Alevizou, P. J., Young, W., \& Hwang, K. (2006). Communication strategies for sustainable technologies: Identifying patterns in consumer behaviour. Paper presented at Greening of Industry Network's 13th International Conference Interaction and Communication: A Clear Route to Sustainability. University of Cardiff.

Miller, G. A. (2003). Consumerism in sustainable tourism: A survey of UK consumers. Journal of Sustainable Tourism, 11(1), 17-39.

Mintel. (1994). The green consumer I: The green conscience. London: Mintel International.

Ottman, I. (1992). Industry's response to green consumerism. Journal of Business Strategy, 3(10), 3-10.

Peattie, K. (2001a). Towards sustainability: The third age of green marketing. The Marketing Review, 2, 129-146.

Peattie, K. (2001b). Golden goose or wild goose? The hunt for the green consumer. Business Strategy and the Environment, 10, 187-199.

Steg, L., Dreijerink, L., \& Abrahamse, W. (2005). Factors influencing the acceptability of energy policies: A test of VBN theory. Journal of Environmental Psychology, 25, 415-425.

Weaver, D. B. (2002). Hard-core ecotourist in lamington national park: Australia. Journal of Ecotourism, 1(1), 19-35.

Weaver, D. B., \& Lawton, L. J. (2002). Overnight ecotourist market segmentation in the gold coast hinterland of Australia. Journal of Travel Research, 40(3), 270-280.

William, O., Bearden, R., Netemeyer, G., \& Haws, K. L. (2011). Multi-item measures for marketing and consumer behavior research (3rd ed.) (pp. 172-173).

Witherspoon, S. (1994). The greening of Britain: Romance and rationality. In R. Jowell, J. Curtis, L. Brook, \& D. Ahendt (Eds.), British social attitudes: The 11th report (pp. 107-139). Aldershot, UK: Dartmouth. 